\title{
Performance Of Shg Linkage Models Adopted By Bankers
}

\author{
*Dr. U.Jerinabi, **S. kavitha, ***S. Deepa \\ *Dean, Faculty of Business Administration, Avinashilingam Institute for Home Science and Higher Education \\ for Women, Coimbatore - 641 043, \\ ** Ph. D Research Scholar, Department of Commerce, Avinashilingam Institute for Home Science and Higher \\ Education for Women, Coimbatore. \\ *** Ph. D Research Scholar, Avinashilingam School of Management Technology, Coimbatore.
}

\begin{abstract}
Economically and socially weak sections of the society lack collateral securities and identity requirements which are important to apply for loan from bank. So these sections of the people find it difficult to approach bank to avail financial services which will help in their economic development and social enrichment. Hence, the SHGs have been organized in which the group jointly takes the responsibility for group borrowing and group repayment. The study were analysed under the following objectives have been set for the present study. (i) To evaluate the Microfinance linkages of SHGs. The study measures the gap in the microfinance linkage by evaluating the three models of linkage. It was conducted in the Coimbatore district of Tamil Nadu covering SHGs of three different models of linkage with sample size 175 SHGs. The primary data was collected through questionnaire. The interview schedule is prepared by discussing with the NGO officials and SHG leaders and SHG members. The results of the study indicate that SHGs have been performing better not only as providers of financial services in terms of augmenting savings, lending and ensuring loan recovery, but also in terms of awareness creation and empowerment.
\end{abstract}

Key words: Micro finance, linkages, Micro credit, management skills

\section{Introduction}

The term microfinance is often confused with the term micro credit and used interchangeably and treated as synonymous. Micro finance is a broad term that includes deposits, loans, payment services and insurances to poor. But micro credit is the "extension of small loans to entrepreneurs too poor to qualify for traditional bank loans" and it does not include savings; hence micro finance is more appropriate term.

\section{Self Help Groups}

The rural poor dues to lack of collateral are ignored by the formal banking system. Moreover, due to illiteracy and ignorance, they are skeptical to approach a formal bank and instead, end up going to the local money lender who in turn exploits them by charging a very high rate of interest.

An SHG is an effort to free the poor from this vicious circle. It is considered as a good platform for the vulnerable to organize themselves and initiate saving behaviour process as well as learn credit transactions. By initiating a self saving mechanism within the group, the poor are able to generate their own loans against their own savings at reasonable rate of interest.

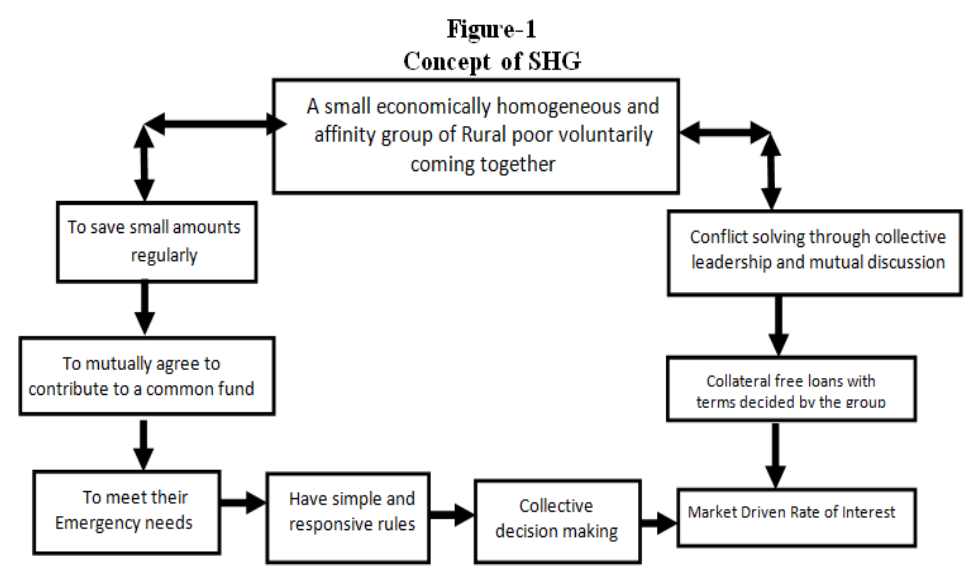

Self Help Group - Linkage Models

There are two types of linkage models adopted by banks to providing financial assistance to SHGs. 


\section{Direct linkage Models:}

\section{Model I - SHGs formed by NGOs and formal agencies, but directly financed by banks.}

In this model NGO acts as a facilitator. NGO would organize the poor into SHGs. They undertake training for awareness building, entrepreneurship and skill training, help in organizing inputs extensions and marketing, introduce saving and internal lending, help in maintenances of accounts and link them with the banks for credit requirements. Banks sanctioned the credit facility to the SHG in the name of the group on the basis of the assessment of SHGs and the recommendation of the NGO. NGOs also keep a watch and ensure satisfactory functioning of the SHGs even after the linkage. This is the most popular SHG-Linkage model in India, where the bank deals directly with individual SHGs. Even other agencies can also act as SHPI here.

Figure-2

Direct Linkage: Model-1

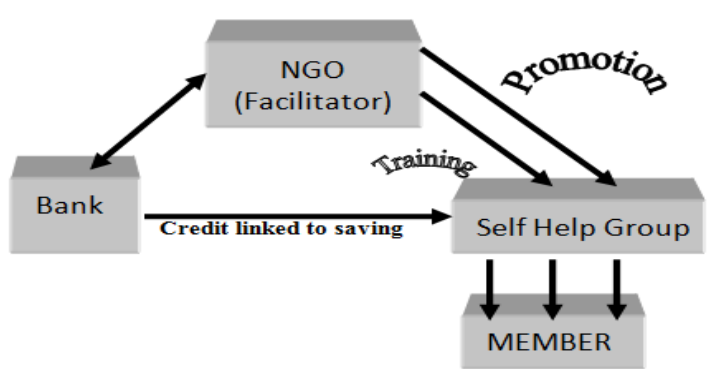

Model II - SHGs formed and financed by banks.

In this model banks directly promote SHG. Here the banks assume to play the role of NGO and ensure linking with SHGs. This integration is very much essential to credit delivery for self employment and other business activities which could be an effective vaccine against poverty. The ultimate goal of this linkage program me is not just a promotion of SHGs but the focus is poverty eradication. It is an established fact that micro credit is an important means of poverty alleviation and SHG is the most trusted medium of the credit delivery to the poor who need most.

Figure: 3

Direct Linkage: Model II

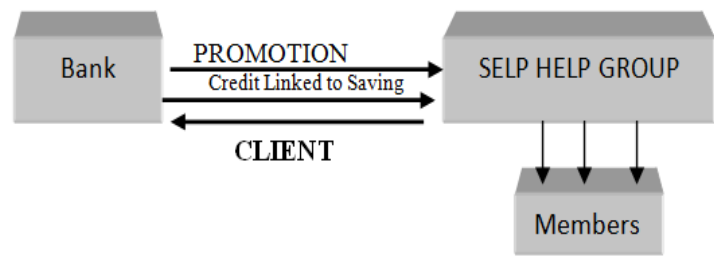

\section{Indirect Linkage Models:}

Model III - SHGs financed by banks using NGOs as Financial Intermediaries.

In this model NGOs play a more proactive role and act as financial intermediary between the bank and the SHGs/individuals for lending. The sanction of credit should take the responsibility of the repayment and would bear the risks of nonpayment. In this respect it is indirect linkage support to the SHGs. Involvement of NGOs in Micro credit system would have a positive influence as they are grass root agencies with good information about borrowers. It takes initiatives informing the groups, nurtures them over a period of time and then provides credit to them after satisfying itself about their maturity to absorb credit.

Figure: 4

\section{Indirect Linkage: Model III}

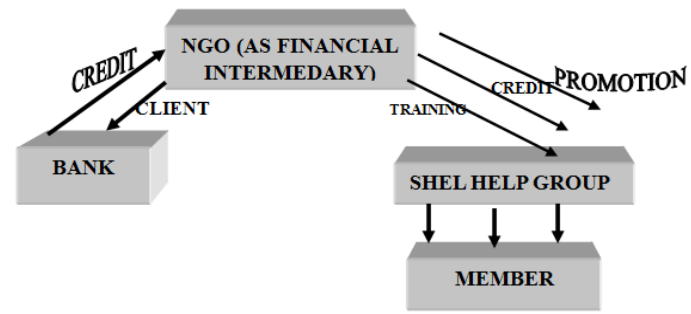




\section{Review Of Literature}

Prasadarao and Gopal (2010) reported a success story of the SHG Bank Linkage program in Andhra Pradesh in comparison with Maharashtra. These two stages have a similar status in population, culture, water resources, soil, and agriculture rural economy and geographically attached. More or less the SHG Bank linkage model introduced in both the states at the same time. In the status up to 2008 - 2009 Andhra Pradesh shows a comparatively higher success rate in Andhra Pradesh than Maharashtra. Empowerment and sustainability are two impact factors of the SHG Bank Linkage model and microfinance, where the rural poor trying to change their life in various parameters to improve their social and even their political status. This effect is also closely related to the group-based methods of intermediation which are used. APMS is one of the key influencing agency in Andhra Pradesh greatly striving towards influencing credit model, government alliance, mentoring and monitoring the SHG Federations.

Purna Chandra Parida and Anushree Sinha (2010) conducted a study on the performance and sustainability of SHGs in India with Gender perspective. The existing literature on sample SHGs bank linkage programs portrays them as an effective tool being used in various countries to approach a range of socio economic issues. As the income-generating activities and other characteristics vary with the gender composition of SHGs, their performance and sustainability vary. The analysis in this study is based on data from a survey carried out in six states in India. Overall, the performance analysis reveals that all -female SHGs perform best. The female SHGs are doing particularly well in terms of recovery of loans and per capital saving. The econometric results indicate that only all-female SHGs are sustainable. The factors that determine the sustainability include recovery of loans, per capital savings, and linkage with an SHG federation.

\section{Objectives Of The Study}

The following objectives have been set for the present study:

- To find out Profiles of SHGs of the sample respondents

- To Analysis Linkage Models adopted by banks in providing financial assistance to SHGs.

- To study the highlights of SHGs - Bank Linkage Programme

- To know the performance of Self Help Groups of three models of linkage

\section{Research Methodology}

The present study attempted to design inclusion strategies based on microfinance SHG linkage models. The study measures the gap in the microfinance linkage by evaluating the three models of linkage. It was conducted in the Coimbatore district of Tamil Nadu covering SHGs of three different models of linkage with sample size 175 SHGs spread among 50 villages of 10 blocks.

\section{Sampling Method}

Multistage purposive Random sampling method is used for the study.

\section{Sample Selection}

SHGs promoted under all the three models of SHG linkages are considered in the sample. There are different types of SHGs present in Coimbatore District. The Types of SHGs are mentioned below:

Model-1: SHGs formed by NGO and directly financed by Banks. NGO extends all supports like forming, training to develop various skills (work related, books maintenance etc.) to SHGs.

Model-II: Banks lend to NGOs and NGOs which in turn finance SHGs.

Model-III: SHGs formed and financed by banks.

\section{Survey Method}

The data was collected from two broad categories of survey research are the questionnaires and the interview. The questionnaires schedule is prepared by SHG members before and after SHG. The interview schedule is prepared by discussing with the NGO officials and SHG leaders and SHG members. Based on the response, the drawbacks in the schedule are noticed and modified.

\section{Period of the study}

The study was conducted for a period of two years from April 2012 to March 2014.

\section{Tools for Analysis of Data}

Different statistical tools were employed for analyzing the data. Descriptive statistics tools such as simple percent age, Mean and Standard Deviation were used on variables to display the data. Frequency table's charts were also used for this purpose. Cross tabulations of variables were prepared to gain valuable insights 
from collecting data. Chi-square tests, ANOVA analysis were selected for the purpose of analyzing the data and testing the hypothesis.

\section{The Profile of the selected SHGs.}

\section{Results For Discussion}

Economically and socially weak sections of the society, lack collateral securities and identity requirements which are important to apply for taken from the bank. So these sections of the people find it difficult to approach bank to avail financial services which will help in their economic development and social enrichment. Hence, the SHGs have been organized in which the group jointly takes the responsibility for group borrowing and group repayment.

\begin{tabular}{|c|c|c|c|c|c|c|c|}
\hline \multicolumn{8}{|c|}{ Table: 1 Tenure of the SHG } \\
\hline \multirow[t]{2}{*}{ S.No } & \multirow[t]{2}{*}{ Tenure } & \multicolumn{2}{|c|}{ Model- I } & \multicolumn{2}{|c|}{ Model II } & \multicolumn{2}{|c|}{ Model III } \\
\hline & & No. & Per cent & No. & Per cent & No. & Per cent \\
\hline 1 & $1-3$ years & - & - & - & - & - & - \\
\hline 2 & $4-6$ years & 75 & 58.3 & 17 & 70.8 & 19 & 86.4 \\
\hline 3 & $7-9$ years & 51 & 39.5 & 7 & 29.2 & 3 & 13.6 \\
\hline \multirow[t]{2}{*}{4} & $10-12$ years & 3 & 2.3 & - & - & - & - \\
\hline & Total & 129 & 100 & 24 & 100 & 22 & 100 \\
\hline \multicolumn{8}{|c|}{ Table :2 Stability of Group SHG } \\
\hline 1 & Stable & 9 & 7.0 & 3 & 12.5 & 2 & 9.1 \\
\hline 2 & Increased & 8 & 6.2 & 4 & 16.7 & 2 & 9.1 \\
\hline \multirow[t]{2}{*}{3} & Decreased & 112 & 86.8 & 17 & 70.8 & 18 & 81.8 \\
\hline & Total & 129 & 100 & 24 & 100 & 22 & 100 \\
\hline \multicolumn{8}{|c|}{ Table :3 Frequency of group meetings } \\
\hline 1 & Weekly & 121 & 93.8 & 14 & 58.3 & 15 & 68.2 \\
\hline 2 & Fortnightly & 6 & 4.7 & 7 & 29.2 & 5 & 22.7 \\
\hline \multirow[t]{2}{*}{3} & Monthly & 2 & 1.5 & 3 & 12.5 & 2 & 9.1 \\
\hline & Total & 129 & 100 & 24 & 100 & 22 & 100 \\
\hline \multicolumn{8}{|c|}{ Table :4 Reason for Lack of Awareness } \\
\hline 1 & Lack of awareness & 97 & 75.2 & 11 & 45.8 & 7 & 31.8 \\
\hline 2 & $\begin{array}{l}\text { Poor to door collection of } \\
\text { saving }\end{array}$ & 11 & 8.5 & 7 & 29.2 & 2 & 9.1 \\
\hline 3 & Not important & 9 & 7.0 & 5 & 20.8 & 8 & 36.4 \\
\hline 4 & No use & 12 & 9.3 & 1 & 4.2 & 5 & 22.7 \\
\hline & Total & 129 & 100 & 24 & 100 & 22 & 100 \\
\hline \multicolumn{8}{|c|}{ Table :6 Decision Making in SHG } \\
\hline 1 & All members-by consensus & 4 & 3.1 & 2 & 8.3 & 2 & 9.1 \\
\hline 2 & All members-by Voting & 58 & 45 & 9 & 37.5 & 6 & 27.3 \\
\hline 3 & Group leaders/representatives & 43 & 33.3 & 5 & 20.8 & 11 & 50 \\
\hline 4 & Link workers/facilitations & 13 & 10.1 & 5 & 20.8 & 1 & 4.5 \\
\hline 5 & Mixed/combination of above & 11 & 8.5 & 3 & 12.5 & 2 & 9.1 \\
\hline & Total & 129 & 100 & 24 & 100 & 22 & 100 \\
\hline \multicolumn{8}{|c|}{ Table:7 Availability and Transparency of Records of SHG } \\
\hline 1 & Yes & 14 & 10.9 & 4 & 16.7 & 3 & 13.6 \\
\hline 2 & Do not Know & 96 & 74.4 & 11 & 45.8 & 11 & 50 \\
\hline \multirow[t]{2}{*}{3} & No & 19 & 14.7 & 9 & 37.5 & 8 & 36.4 \\
\hline & Total & 129 & 100 & 24 & 100 & 22 & 100 \\
\hline \multicolumn{8}{|c|}{ Table: 8 Leadership Rotation } \\
\hline 1 & Once in 6 months & 7 & 5.5 & 2 & 8.3 & 2 & 9.1 \\
\hline 2 & Once in a year & 68 & 52.7 & 9 & 37.5 & 7 & 31.8 \\
\hline 3 & Once in 2 years & 36 & 27.9 & 8 & 33.4 & 5 & 22.7 \\
\hline \multirow[t]{2}{*}{4} & On rotation & 18 & 13.9 & 5 & 20.8 & 8 & 36.4 \\
\hline & Total & 129 & 100 & 24 & 100 & 22 & 100 \\
\hline & ble : 9 Level of Lending to the & embe & & & & & \\
\hline 1 & Increased & 17 & 13.2 & 3 & 12.5 & 2 & 9.1 \\
\hline 2 & Same & 34 & 26.4 & 14 & 58.3 & 8 & 36.4 \\
\hline 3 & Decreased & 78 & 60.4 & 7 & 29.3 & 12 & 54.4 \\
\hline & Total & 129 & 100 & 24 & 100 & 22 & 100 \\
\hline & ble: 10 Trainings Received by $\mathrm{S}$ & HG Mc & & & & & \\
\hline 1 & $20-40$ & 23 & 17.8 & 5 & 20.8 & 4 & 18.2 \\
\hline 2 & $41-60$ & 18 & 14.0 & 96 & 25 & 8 & 36.4 \\
\hline 3 & $61-80$ & 53 & 41.1 & 9 & 37.5 & 7 & 31.8 \\
\hline 4 & $81-100$ & 35 & 27.1 & 4 & 16.7 & 3 & 13.6 \\
\hline & Total & 129 & 100 & 24 & 100 & 22 & 100 \\
\hline & ble :12 Problems in SHGs & & & & & & \\
\hline 1 & Groups Internal conflicts & 25 & 19.4 & 3 & 12.5 & 3 & 18.2 \\
\hline 2 & Default in loan & 43 & 33.3 & 5 & 20.8 & 4 & 18.2 \\
\hline
\end{tabular}


Performance Of Shg Linkage Models Adopted By Bankers

\begin{tabular}{|c|c|c|c|c|c|c|c|}
\hline 3 & Migration of member & 23 & 17.8 & 3 & 12.5 & 2 & 9.1 \\
\hline 4 & $\begin{array}{l}\text { Not following the rules and } \\
\text { regulations }\end{array}$ & 11 & 8.5 & 4 & 16.7 & 3 & 1.6 \\
\hline 5 & Leadership problem & 5 & 3.9 & 2 & 8.3 & 2 & 9.1 \\
\hline 6 & Lack of marketing support & 18 & 14 & 4 & 16.7 & 2 & 9.1 \\
\hline 7 & Lack of NGOs support & 4 & 3.1 & 3 & 12.5 & 5 & 22.7 \\
\hline & Total & 129 & 100 & 24 & 100 & 22 & 100 \\
\hline \multicolumn{8}{|c|}{ Table :13 Suggestion provided for the Development of SEGs } \\
\hline 1 & Formation of SHG federation & 40 & 31 & 7 & 29.2 & 7 & 31.8 \\
\hline 2 & Large loan amount & 31 & 24 & 6 & 25 & 5 & 22.8 \\
\hline 3 & Training and workshop & 30 & 23.3 & 6 & 25 & 6 & 27.2 \\
\hline \multirow[t]{2}{*}{4} & $\begin{array}{l}\text { Marketing support for SHG } \\
\text { members }\end{array}$ & 28 & 21.7 & 5 & 20.8 & 4 & 18.2 \\
\hline & Total & 129 & 100 & 24 & 100 & 22 & 100 \\
\hline
\end{tabular}

Source: primary data

The above table 1. Tenure of the SHG reveals that the majority 58.1 per cent of Model I SHGs, 70.8 per cent model II SHGs and 86.4 per cent of model III SHGs have been in existence for about 4-6 years. The remaining groups were about 7-9 years old excluding the 2.3 per cent of model I SHGs which were about 10-12 years old. SHGs which were about $10-12$ years old.

Table 2. The Size of sample SHGs shows that the majority of the sample groups had either 9-12 members or 12-15 members in their groups. Nearly three fourth of the groups had reported that their group size had decreased over time.

From the Table 3 Frequency of group meetings were conducted on a weekly basis by 93.8 per cent of the SHGs of the model I linkage, and 58.3 per cent of the SHGs of the model II linkage and 68.2 per cent of model III SHGs. From the Table 4. Lack of awareness on the importance of the meeting was the main reason for the low attendance of members. Some of the SHG members of Model II (20.8 per cent) and model III (36.4 per cent) also had the opinion that the attendance was not so important for all the meetings.

The Table 5 Motivation to Join SHG reveals the details of the motivating agents who encouraged the members to join SHGs. Out of the total 1293 members of SHGs of the model I Linkage, the majority (58.7 per cent) have joined SHGs through the motivation given by the NGO workers or government officials and 42.9 per cent of respondents of the SHGs of Model II Linkage had joined SHGs by the motivation of friends or relatives. Among the respondents of the SHGs of model III linkage 31.6 per cent have joined SHGs by the motivation of the friends or relatives and another 31.6 per cent have joined SHGs by the motivation of the banks or government officials.

From the Table 6 Decision Making in SHG, majority (45 per cent) of the model I SHGs, 37.5 per cent of model II SHGs and 27.3 per cent of model III SHGs stated that decisions were made by all the members of SHG by casting Votes.

Among the Table 7. responses from the SHGs are regarding the transparency and the awareness on the books of accounts, records and registers of SHGs, 10.9 per cent of Model I SHGs, 16.7 per cent of Model II SHGs and 13.6 per cent of Model III SHGs have responded positively for proper maintenance of all the recodes and that there is transparency in those. The majority of the groups stated that the records were maintained by the group leaders or the bookkeepers and not all members were aware of it.

The Table: 8 Leadership Rotation also reveals that the majority (52.7 per cent) of the model I SHGs, 37.5 per cent of the model II SHGs and 31.8 per cent of Model III SHGs shows changed their leaders once in a year. Another 27.9 per cent of the SHGs of model I and 33.4 per cent of model II SHGs have changed their leaders once in 2 years. 36.4 per cent of the SHGs of model III linkage reported that there was no rotation of leadership in their groups.

The above Table: 9 Level of Lending describes that majority 60.4 per cent of model I SHGS and 54.5 per cent of model III SHGs reported a decrease in their lending level to the members after the bank linkage. 58.3 per cent of model II SHGs reported that the lending level was the same even after bank linkage. The groups managed their financial needs on their own and also the bank loan was equally shared among the members. Thus, these groups have registered a decrease in their lending level to the members.

The above Table: 10 Training Received by SHG members revealed that the majority 41.1 per cent of the model I SHGs and 37.5 per cent Model II SHGs and 31.8 per cent of the model III SHG revealed that 61-80 per cent of their members attended training programmers.

From the Table: 11 Benefits of Trainings, it is clear that the confidence building was the major benefit of the training programmers with the mean score value of $4.20,4.17$ and 4.13 i.e., it revealed that confidence building, skill development and marketing linkage were some of the major benefits derived by SHG members with higher mean score values.

It is found from the Table: 12 Problems in SHGs, that the major problem faced by the sample SHGs of the three models of linkage was default in loan, violating the rules and regulations, migration of members and 
conflicts among group members were the problem faced by SHGs of model II linkage in their operation. Internal conflicts, default on loan and lack of NGO support were major problems faced by SHGs of model III linkage in their operation.

The above Table: 13 Suggestion provided in the Development of SEGs revealed that the 175 groups interviewed and the respondents opined that formation of SHG federations, providing large loan amount, providing training and workshops for SHG members and marketing support for SHG products were equally important for the development of SHGs.

\section{Details of Self Help Group - BLP Profile:}

SHG-Bank Linkage programme has been promoting MF facilities to the poor. Almost from the same period, the financial sector has been witnessing the market oriented reforms. The focus in the period of reforms was on enhancing the efficiency and profitability of the banking system, neglecting the needs of the disadvantaged sections of society. It widens the gap of rich poor in availing institution financial services mainly borrowing. The SHG bank linkage programme in which SHGs save small amounts of money and open an account in bank, later they avail credits from bank after their successful operation for atleast six months. Thus SHG-BLP was considered to fill the existing gap in the formal financial network and extending the outreach of banking to the poor.

\begin{tabular}{|c|c|c|c|c|c|c|c|c|}
\hline \multicolumn{9}{|c|}{ Table: 14 Number of Loan taken from the bank } \\
\hline \multirow[t]{2}{*}{ S.No } & \multirow{2}{*}{\multicolumn{2}{|c|}{ Number of Loan taken }} & \multicolumn{2}{|c|}{ Model- I } & \multicolumn{2}{|c|}{ Model II } & \multicolumn{2}{|c|}{ Model III } \\
\hline & & & No. & Per cent & No. & Per cent & No. & Per cent \\
\hline 1 & \multicolumn{2}{|l|}{ Once } & 87 & 67.4 & 16 & 66.7 & 15 & 68.2 \\
\hline 2 & \multicolumn{2}{|l|}{ Twice } & 23 & 17.8 & 7 & 29.2 & 6 & 27.3 \\
\hline 3 & \multicolumn{2}{|l|}{ Thrice } & 14 & 10.9 & 1 & 4.1 & 1 & 4.5 \\
\hline \multirow[t]{2}{*}{4} & \multicolumn{2}{|l|}{ More than thrice } & 5 & 3.9 & - & - & - & - \\
\hline & \multicolumn{2}{|l|}{ Total } & 129 & 100 & 24 & 100 & 22 & 100 \\
\hline \multicolumn{9}{|c|}{ Table :15 Utilisation of Loan } \\
\hline 1 & \multicolumn{2}{|c|}{ Consumption - education } & 36 & 27.1 & 7 & 29.2 & 6 & 27.3 \\
\hline 2 & \multicolumn{2}{|l|}{ Consumption - others } & 45 & 34.9 & 11 & 45.8 & 10 & 45.5 \\
\hline 3 & \multicolumn{2}{|l|}{ Production purpose } & 28 & 21.7 & 2 & 8.3 & 2 & 9.1 \\
\hline 4 & \multicolumn{2}{|l|}{ Assets } & 11 & 8.5 & 2 & 8.3 & 2 & 9.1 \\
\hline 5 & \multicolumn{2}{|l|}{ Others } & 9 & 7 & 2 & 8.3 & 2 & 9.1 \\
\hline & \multicolumn{2}{|l|}{ Total } & 129 & 100 & 24 & 100 & 22 & 100 \\
\hline \multicolumn{9}{|c|}{ Table : 16 Bank loan Repayment schedule } \\
\hline 1 & 12 months & & 2 & 1.5 & - & - & - & - \\
\hline 2 & 24 months & & 61 & 47.3 & 11 & 45.3 & 3 & 13.6 \\
\hline 3 & 36 months & & 27 & 20.9 & 9 & 37.5 & 5 & 22.7 \\
\hline 4 & 48 months & & 30 & 23.3 & 2 & 8.3 & 9 & 40.9 \\
\hline 5 & 60 months & & 9 & 7.0 & 2 & 8.3 & 5 & 22.7 \\
\hline & Total & & 129 & 100 & 24 & 100 & 22 & 100 \\
\hline & le:17 Level of Conven & ience with th & Repay & edule & & & & \\
\hline 1 & Extremely convenienc & & 23 & 17.8 & 4 & 16.7 & 2 & 9.1 \\
\hline 2 & Very convenience & & 46 & 35.7 & 2 & 8.3 & 8 & 36.4 \\
\hline 3 & Somewhat convenienc & & 24 & 18.6 & 7 & 29.2 & 7 & 31.8 \\
\hline 4 & Slightly convenience & & 11 & 8.5 & 8 & 33.3 & 2 & 9.1 \\
\hline 5 & Not at all convenience & & 25 & 19.4 & 3 & 12.5 & 3 & 13.6 \\
\hline & Total & & 129 & 100 & 24 & 100 & 22 & 100 \\
\hline & ble : 18 Frequency of $\mathrm{D}$ & iscussion Be & een B & ial and $\mathrm{SH}$ & bout & it Schedu & & \\
\hline 1 & Never & & 11 & 8.5 & 2 & 8.3 & 1 & 4.6 \\
\hline 2 & Rarely & & 14 & 10.7 & 5 & 20.8 & 2 & 9.1 \\
\hline 3 & Sometimes & & 24 & 18.7 & 9 & 37.5 & 3 & 13.6 \\
\hline 4 & Often & & 50 & 38.7 & 5 & 20.8 & 6 & 27.3 \\
\hline 5 & Always & & 30 & 23.4 & 3 & 12.5 & 10 & 45.4 \\
\hline & le : 19 Awareness of $t$ & he terms and & onditic & & & & & \\
\hline 1 & Terms and Conditions & Yes & 14 & 10.9 & 4 & 16.7 & 3 & 13.6 \\
\hline & of Loan & No & 3 & 2.3 & 2 & 8.3 & 2 & 9.1 \\
\hline & & Sometimes & 112 & 86.8 & 18 & 75 & 17 & 77.3 \\
\hline 2 & Feedback regardin & Yes & 14 & 10.9 & 4 & 16.7 & 2 & 9.1 \\
\hline & quality of financia & No & 12 & 9.3 & 3 & 2.5 & 2 & 9.1 \\
\hline & products & Sometimes & 103 & 79.8 & 17 & 70.8 & 18 & 81.8 \\
\hline 3 & Responsive the & Yes & 15 & 11.6 & 4 & 16.7 & 2 & 9.1 \\
\hline & SHGs & No & 12 & 9.3 & 3 & 12.5 & 2 & 9.1 \\
\hline & & Sometimes & 102 & 79.1 & 14 & 70.9 & 18 & 81.8 \\
\hline & ble: 20 Supervision of & the SHGs & & & & & & \\
\hline 1 & NGO & & 63 & 48.8 & 7 & 29.2 & 5 & 22.7 \\
\hline 2 & Bank & & 18 & 13.9 & 5 & 20.8 & 4 & 18.2 \\
\hline 3 & SHG federation & & 32 & 24.8 & 5 & 20.8 & 11 & 50 \\
\hline
\end{tabular}


Performance Of Shg Linkage Models Adopted By Bankers

\begin{tabular}{|l|l|l|l|l|l|l|l|}
\hline 4 & Financial Institution & 6 & 4.6 & 1 & 4.2 & - & - \\
\hline 5 & Government & 9 & 7.0 & 3 & 12.5 & 2 & 9.1 \\
\hline 6 & No need of supervision & 1 & 0.8 & 3 & 12.5 & - & - \\
\hline & Total & 129 & 100 & 24 & 100 & 22 & 100 \\
\hline
\end{tabular}

Source: primary data

Above the Table :15 Utilisation of Loan more than 25 percent of the SHGs from three models of linkages have utilized the loan for the educational purpose. Nearly 45 per cent of model II and model III SHGs and 35 percent of the model I SHGs have utilized the loan of various consumption purposes like marriage, festivals, repayment of loan ect.

Among the Table: 16 SHGs were convenient with the repayment schedules offered by the banks only 19.4 per cent of SHGs of the model I linkage, 12.5 per cent of SHGs of model II linkage and 13.6 per cent of the SHGs of model III linkage expressed that they were not at all convenient with the repayment schedules.

From the table: 17 Frequency of Discussions Between bank official and SHGS about repayment schedule, the majority (38.7 per cent) of the model I SHG member stated that the bank officials often discuss with them about the repayment schedule where as model II SHG members (37.5 per cent) stated that the bank officials sometimes discussed while the 45.4 percent of model III SHGs revealed that the bank officials always discuss with them about the repayment schedule.

The above Table: 18 Awareness of the terms and conditions of the loan, regarding the bank officials explaining the terms and conditions of a loan, looking for feedback about the quality of their products or services and their response to SHG member's suggestion, more than 75 per cent of the SHGs have responded that sometimes the bank officials interacted with them regarding the above.

Regarding the Supervision of SHGs, 48.8 per cent of the model I SHGs, 29.2 per cent of model II SHGs and 22.7 per cent of model III SHGs opined that NGOs have to take the responsibility of supervising the SHGs for their better performance. Majority (50 per cent) of the SHGs from the model III linkage have expressed that SHG federations need to be formed and these federations have to take up the supervision of SHGs to ensure their quality.

\section{Performance of SHGs of Three models of Linkage:}

In this chapter an attempt is made to analyze the functional and management aspects of the selected SHGs. As the SHGs aim not just providing Micro credit to SHGS members but focusing on the overall development of poor people. This analysis involves their steps. (1) Functioning of the SHGs, (2) Assigning weights to the indicators and (3) Calculation of composite weight for each SHG.

\begin{tabular}{|c|c|c|c|c|c|c|}
\hline \multicolumn{7}{|c|}{ Table: 21 Performance Index for Model-I: SHGs } \\
\hline \multirow{2}{*}{$\begin{array}{l}\text { Performance } \\
\text { Index }\end{array}$} & \multirow[t]{2}{*}{ No. of SHGs } & \multicolumn{3}{|c|}{ Performance Index } & \multirow{2}{*}{$\begin{array}{l}\text { Percentage of } \\
\text { SHGs }\end{array}$} & \multirow[t]{2}{*}{$\mathrm{F}$ value } \\
\hline & & Minimum Score & Maximum Score & Mean Score & & \\
\hline Poor & 34 & 15 & 18 & 17.42 & 25.8 & \multirow[t]{3}{*}{$230.36^{*}$} \\
\hline Medium & 57 & 19 & 20 & 19.83 & 44.5 & \\
\hline Good & 38 & 21 & 26 & 22.00 & 29.7 & \\
\hline Total & 129 & 15 & 26 & 19.59 & 100 & \\
\hline \multicolumn{7}{|c|}{ Table: 22 Performance Index for Model-II :SHGs } \\
\hline Poor & 9 & 16 & 19 & 17.67 & 37.5 & \multirow[t]{3}{*}{$31.5^{* *}$} \\
\hline Medium & 9 & 20 & 20 & 20.00 & 37.5 & \\
\hline Good & 6 & 21 & 25 & 22.17 & 25.0 & \\
\hline Total & 24 & 16 & 25 & 19.67 & 100 & \\
\hline \multicolumn{7}{|c|}{ Table: 23 Performance Index for Model-III :SHGs } \\
\hline Poor & 8 & 13 & 18 & 16.57 & 36.36 & \multirow[t]{3}{*}{$50.61^{* *}$} \\
\hline Medium & 9 & 19 & 21 & 20.20 & 40.91 & \\
\hline Good & 5 & 22 & 25 & 23.17 & 22.73 & \\
\hline Total & 22 & 13 & 25 & 19.87 & 100 & \\
\hline
\end{tabular}

Source: primary data

The analysis revealed that 29.7 per cent of model I SHGs were performing food, whereas 25 per cent of Model II SHGs and 22.73 per cent of Model III SHGs were performing good. Only 25.8 per cent of model I SHGs were performing poor whereas 37.5 per cent of model II SHGs and 36.36 per cent of model III SHGS were performing poor. Since the ' $F$ ' value is significant the null hypothesis of no difference in the mean score on the performance index among the groups is rejected.

\section{Conclusion:}

This study shows evidence that the SHG members are learning financial discipline through their SHG activities and they are also aware of the importance and advantages of using formal financial services. The results of the analysis suggest that SHGs have been performing better not only as providers of financial services in terms of augmenting savings, lending and ensuring loan recovery, but also in terms of awareness creation and 
empowerment. They also lead to the development of human resources and management skills, leadership and motivation through the trainings provided to them. The present study also proved that the SHGs that are promoted by NGOs and directly financed by banks outrun the other SHG models in terms of their performance.

\section{Books:}

\section{Bibliography}

[1]. Daniel Lazar, P. Natarajan and malabika Deo, "Micro Finance- enabling empowerment", Vijay Nicole imprints private limited, 2010 .

[2]. Lalitha. N and B.S Nagarajan, "SHGs in Rural Development", Dominant Publishers and Distributors, New Delhi, 2002.

[3]. Manabsen, "Study of SHGs and Micro Finance in West Bengal", State institute of Panchayats and Rural Development and Dasgupta and Company, Kolkata, 2005.

\section{Journals}

[4]. Prasadarao. M and R. Gopal, "Self Help Group Bank Linkage-Paradigm of Success", Online journal, 2010.

[5]. PurnaChandra Parida and Anushree Sinha, "Performance and sustainability of SHGs in India: A gender perspective, Asian Development Review", Vol., 27, No.1, PP.80-103.

[6]. H.M. Chandrashekar and Lokesh M.V., "Role of SHGs in socio-economic change of Vulnerable poor", International NGO Journal Vol.4 (4). PP. 127-131, April 2009, ISSN: 1993-8225.

[7]. Nedumaran, S., Palanisami, K. and Swaninathan, L.P, "Performance and Impact of SHGs in TamilNadu", Indian Journal of Agurcilucre Economics, July, 2001.

\section{Web site:}

1. www.acadermicjournals.org

2. www.microjournal.com

3. www.ssrn.com

4. www.scribd.com

5. www.adb.org 